\title{
MOBILIDADE CORPORATIVA - DESAFIOS PARA ELABORAÇÃO E IMPLEMENTAÇÃO NO BRASIL
}

Luiz Afonso Penha de Sousa

Mestre em Engenharia de Transportes pela UFRJ, Rio de Janeiro, RJ, Brasil Professor do Departamento de Engenharia Civil - CEFET/RJ

Luiz.sousa@cefet-rj.br

\author{
Carolina Alves Arrais da Silva
}

Graduada em Engenharia Civil carolina.alves.a@gmail.com

Marina Leite de Barros Baltar

Mestre em Engenharia de Transportes pela UFRJ, Rio de Janeiro, RJ, Brasil Professora do Departamento de Engenharia de Transportes da UFMT mabaltar@gmail.com

\section{RESUMO}

Os congestionamentos nas áreas urbanas durante os horários de pico estão diretamente relacionados aos deslocamentos por motivos de trabalho. Este fato revela as empresas como uma potencial fonte capaz de auxiliar os gestores públicos na gestão da demanda por viagens (GDV). Nesse sentido, surge o conceito de mobilidade corporativa, ainda pouco difundido e explorado no Brasil. Com base em experiências internacionais, os empregadores podem obter dados essenciais ao desenvolvimento de planos de transportes, como informações dos fluxos diários de origemdestino, geralmente obtidos por custosas pesquisas domiciliares. Os planos de mobilidade corporativa (PMC) mostram-se uma boa forma de GDV a ser aplicada em grandes cidades. Paralelamente, alguns países incentivam estas atitudes através de políticas públicas conhecidas como Trip Reduction Ordinances (TRO), existentes desde a década de 80 nos Estados Unidos. Este trabalho tem como objetivo pesquisar as melhores práticas de mobilidade corporativa encontradas em cidades dos Estados Unidos e de países da Europa, bem como a bibliografia dos autores mais relevantes neste tema. Foram identificadas as principais possibilidades de aplicação de PMCs e TROs em regiões metropolitanas brasileiras, bem como as barreiras que serão encontradas para a efetividade e eficácia dessas medidas. Destaca-se a necessidade de mais estudos relacionados à elaboração e implementação de políticas de mobilidade corporativa nas cidades brasileiras.

Palavras-chave: Mobilidade corporativa. Gestão da demanda de viagens. Trip reduction ordinances. Pólos geradores de viagens. Políticas públicas.

\begin{abstract}
Congestion caused in urban areas during peak periods is directly related to commuting traffic. This fact reveals companies as an important source capable of assisting public authorities in travel demand management (TDM). In this sense, the concept of corporate mobility emerges, still sparse in Brazil. Based on international experiences, employers can obtain essential data to the development of transportation, such as information on daily origin-destination flows, often obtained by costly household surveys. The development of Corporate Mobility Management (CMM) is a good way to TDM enforcement in big cities. In parallel, some countries encourage these attitudes through public policies known as Trip Reduction Ordinances (TRO), which have been applied since the 1980s in the United States. The present project consideres the best practices found
\end{abstract}


in United States and European countries' cities, and also covers the bibliography of the most relevant authors on the theme of corporate mobility. The main possibilities of application of CMM and TROs in Brazilian metropolitan regions were identified, as well as the barriers that will be faced for the effectiveness of the implementation. It is important to highlight the need for more studies related to the elaboration and implementation of TROs in Brazilian cities.

Keywords: Corporate mobility, Travel demand management, Trip reduction ordinances, Traffic generators, Public policies.

\section{INTRODUÇÃO}

Os altos índices de concentração pessoas nos centros urbanos são um dos fatores que impactam no número de deslocamentos nas grandes cidades brasileiras. Pesquisas recentes (Firjan, 2015) demonstram que $45 \%$ da população brasileira vive em $11 \%$ das cidades no Brasil. 0 constante aumento do número de automóveis corrobora com a instalação de uma crise de mobilidade urbana no país.

Regiões urbanas com grande concentração de postos de trabalhos geram diversos impactos sentidos pela sociedade. De acordo com pesquisas da WRI Brasil (2015), metade dos deslocamentos que ocorrem diariamente no Brasil tem como destino os locais de trabalho. Estas viagens têm causado consequências às pessoas e às cidades, principalmente quando observados horários específicos do dia, considerados os horários de pico, usualmente escolhidos pelos empregadores como horários de chegada e saída do trabalho. Ao classificar a participação social no planejamento da mobilidade urbana em quatro grandes modalidades (participações assistencialista, corporativa, eleitoral e política) no Plano Nacional de Mobilidade Urbana (2007), o Ministério das Cidades demonstra sua intenção em fomentar um processo participativo, dando margem à abrangência das empresas na elaboração deste processo (Brasil, 2012). Essa orientação abre espaço para a discussão da mobilidade corporativa a partir do momento que considera as empresas como atores principais na capacidade de realizar a gestão da demanda de viagens (GDV).

O objetivo da pesquisa é realizar um estudo acerca das soluções de mobilidade corporativa adotadas no cenário internacional, trazendo-as para a realidade das grandes cidades brasileiras na busca por estratégias de implantação de políticas públicas adequadas às dificuldades de mobilidade apresentadas diariamente nos centros urbanos.

A metodologia adotada consiste em apresentar as características e as diferentes soluções de mobilidade corporativa encontradas no cenário internacional. Por meio da revisão bibliográfica, o trabalho apresenta uma descrição dos cenários nacional e internacional no que diz respeito às políticas públicas de incentivo à implantação da mobilidade corporativa por parte dos 
empregadores.

\section{MOBILIDADE CORPORATIVA}

No contexto corporativo, as questões relacionadas ao transporte resultam em diversos transtornos às empresas e aos funcionários. As estratégias de mobilidade corporativa buscam dar estímulos para que os trabalhadores que se deslocam diariamente optem por meios de transporte mais sustentáveis nas viagens a trabalho.

Embora não possam controlar ou impor o modo como os funcionários se deslocam para o trabalho, as empresas desempenham um papel fundamental nesta escolha. Por meio de ações de mobilidade corporativa é possível estimular os funcionários a mudanças de hábito e à opção por escolhas mais sustentáveis e eficientes em relação ao automóvel. Dessa forma, as empresas possuem extrema relevância em relação a iniciativas de GDV (Petzhold e Almeida, 2016).

Nesse estudo, os mesmos autores constataram que falta iniciativa por parte das empresas examinadas a fim de estimular os funcionários a optarem por meios mais sustentáveis de transporte. Isso corrobora com o fato de existir uma grande disparidade entre o incentivo dado ao uso do veículo individual motorizado frente aos meios de transporte mais sustentáveis.

Na mesma pesquisa os autores observaram que, no que diz respeito ao transporte público coletivo, as empresas limitam-se a apenas seguir o disposto na lei (Brasil, 1988), descontando os 6\% do salário do funcionário em folha, notando-se pouco ou nenhum incentivo ao seu uso. Em relação ao transporte individual não motorizado, a situação mostra-se ainda mais crítica, uma vez que bicicletas e caminhadas, de maneira geral, não recebem qualquer tipo de incentivo. Em contrapartida, o uso do automóvel individual recebe diversos incentivos, como vagas gratuitas de estacionamento e auxílio combustível.

Analisando o tempo médio de viagem para o trabalho de diversas cidades do mundo, as cidades de São Paulo e Rio de Janeiro ocupam a 2a e 3a colocação respectivamente (Figura 1). Nelas, em média, são necessários mais de 40 minutos para realizar o trajeto Casa x Trabalho.

Com objetivo de aumentar a participação das empresas no modo de deslocamento dos funcionários, foi desenvolvido o Plano de Mobilidade Corporativa (PMC) que apresenta metodologias direcionadas à melhoria da mobilidade dentro das empresas por meio de um planejamento com medidas estruturadas.

Esse plano busca influenciar a forma como o funcionário se desloca a trabalho, tanto com relação ao transporte quanto ao horário escolhido, e é composto por medidas integradas que visam 
promover deslocamentos mais sustentáveis e trazer benefícios para a organização, os funcionários e a região (Embarq Brasil, 2015).

Figura 1: Tempo médio no deslocamento casa-trabalho - regiões metropolitanas selecionadas no Brasil e no mundo (em minutos)

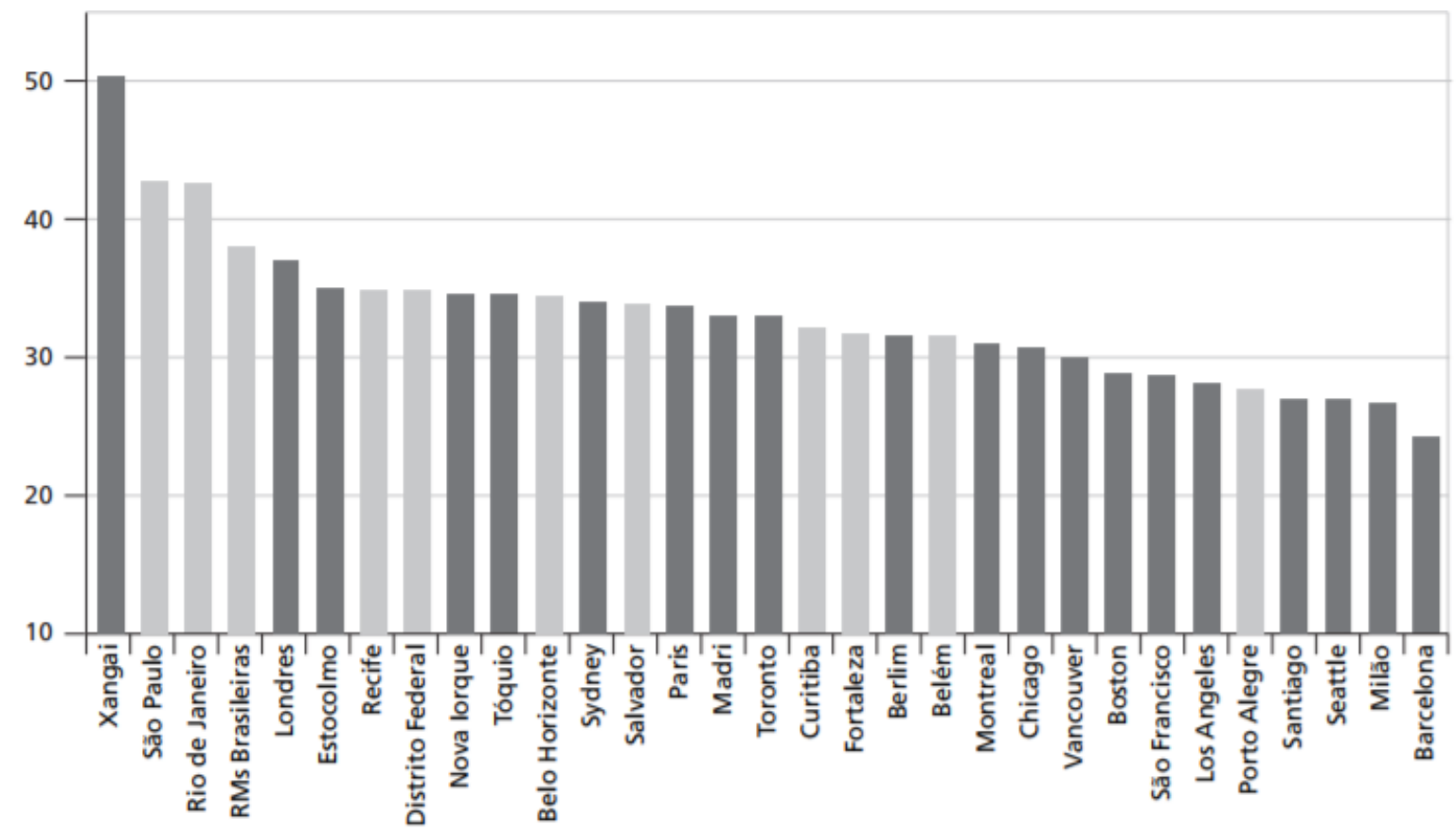

Fonte: Pereira e Schwanen (2013)

2.1 Gestão da demanda de viagens (GDV)

A gestão da demanda de viagens (GDV) faz referência às políticas e aos programas criados para reduzir o número de viagens realizadas diariamente, permitindo um sistema de transportes mais eficiente, efetivo e sustentável. Essas políticas encorajam o uso de modos de transporte alternativos ao automóvel particular (caminhada, bicicleta, transporte coletivo), com o objetivo principal de promover a mobilidade sustentável, buscando-se atender às necessidades das pessoas e das organizações (Decastro, 2014) a partir da combinação de políticas públicas e soluções do setor privado (The City Fix Brasil, 2017).

As empresas são organizações propícias para a implementação de planos de GDV, não apenas por serem grandes polos geradores de viagens, mas principalmente por terem acesso aos dados da rotina de deslocamento de seus funcionários. Neste âmbito, diversas cidades no mundo utilizam técnicas de gestão de demanda de viagens alinhadas às viagens geradas pelas empresas, de acordo com critérios e metodologias pré-estabelecidos, buscando que as empresas contribuam com um melhor sistema de mobilidade (Embarq Brasil, 2015).

O TCRP (2003) relata os principais desafios encontrados por empresas que já colocaram em 
prática planos de mobilidade corporativa (PMC). O principal ponto destacado refere-se à falta de opções de transportes disponíveis, ou seja, há empresas localizadas em locais de difícil acesso, e por isso recebem pouca oferta de transporte público. De forma geral, com base na observação de PMCs já existentes, os seguintes pontos devem ser destacados (EY-Mobilize Brasil, 2015; TCRP, 2003; SAP, 2016):

- Empresas com mais de 1000 funcionários e com localidades descentralizadas tendem a encontrar mais dificuldades na implementação de seus planos se comparadas às empresas menores;

- A atitude do empregador é um diferencial. Em empresas menores, o apoio da alta diretoria se mostra como um fator-chave para o sucesso do PMC. Já em grandes empresas, os responsáveis pela implantação do PMC pouco cooperativos muitas vezes acabam por ser culpados pelas dificuldades encontradas no programa. Fatores como custos administrativos devem ser previstos;

- Não existe uma única solução completa que atenda a todos os perfis de viagens.

\subsection{Atrativos às empresas}

A mobilidade corporativa pode ser uma boa oportunidade para as empresas aumentarem a eficiência na utilização dos meios de transportes utilizados pelos trabalhadores. Dessa forma, a imagem corporativa também é beneficiada, uma vez que a GDV pode auxiliar a empresa a atingir suas metas de sustentabilidade.

Pesquisa conduzida por WRI Cidades (2017) demonstrou que investir em vagas de estacionamento, auxílio combustível, veículos corporativos e táxis ajudam a estimular o uso do transporte motorizado individual. A pesquisa revelou também que em média $60 \%$ do orçamento com deslocamentos de funcionários é direcionado a políticas voltadas para o uso do carro. Comparativamente, um funcionário com vaga de estacionamento gratuita recebe um benefício $44 \%$ maior que um funcionário que recebe vale transporte.

Entre os benefícios dos PMC está o aumento da qualidade de vida dos funcionários. $\mathrm{O}$ ranking "As 100 Melhores Empresas" eleitas pela Revista Fortune demonstra que 90\% destas possuem estratégias de mobilidade corporativa (Embarq Brasil, 2015). Observa-se ainda um aumento de produtividade dos funcionários e que a capacidade de retenção e contratação de talentos sobe frente a mercados competitivos.

De acordo com EY-Mobilize Brasil (2016), alguns dos benefícios para as empresas 
decorrentes da implementação de um PMC são:

- Redução no número de faltas;

- Diminuição nos gastos com saúde;

- Diminuição da rotatividade/retenção de talentos;

- Melhoria na produtividade;

- Ganhos de imagem corporativa;

- Redução dos custos com transportes e estacionamentos;

- Otimização de frotas.

\subsection{Experiências internacionais}

A participação das empresas no gerenciamento da demanda por transportes é discutida em diversos países da União Europeia, da Ásia, da Oceania e nos Estados Unidos desde o início dos anos 1990.

Algumas soluções comumente adotadas para GDV internacionalmente são: faixas exclusivas para veículos com mais de 1 ou 2 passageiros além do motorista, dependendo da legislação local; restrição da capacidade viária, com destinação de faixas exclusivas para ônibus; restrição da circulação de veículos por dia da semana, de acordo com a placa; restrição de acesso de veículos de carga em determinados horários de pico da manhã e da tarde; entre outros (CALTRANS, 2016; RIO ÔNIBUS, 2016; PDTU-RMRJ,2013; CET-SP, 2017).

No Reino Unido, em 2013, foi realizada uma pesquisa mostrando que pequenos aumentos em caminhadas ou ciclismo para o transporte podem contribuir para a saúde da população. Foram analisadas características individuais, de trabalho e ambiente. Os resultados mostraram que as pessoas sem acesso a estacionamento no local de trabalho e que relataram ambientes mais favoráveis para caminhadas e ciclismo no caminho foram mais propensas a ir a pé ou de bicicleta (Panter et al, 2013).

Portanto, intervenções que fornecem rotas agradáveis e convenientes, limitam ou cobram estacionamento do veículo no local de trabalho, e fornecem estacionamento gratuito fora do local podem ser incentivos a passageiros de carro para que incorporem a caminhada e o ciclismo em vias que utilizam regularmente os veículos de passeio (Panter et al, 2013).

Um ponto importante a ser citado é que algumas empresas encontram dificuldades em implantar o PMC devido à grande complexidade associada ao seu desenvolvimento. Como exemplo, a empresa Caterpillar, lotada em Miami, Flórida, que, em busca de tornar ampla a visibilidade do 
plano tanto internamente como no âmbito social, envolveu diversas áreas da companhia (Recursos Humanos, Benefícios, Transportes, Estacionamento, Gerência, Jurídico, Meio Ambiente e Relações Públicas), tornando o plano complexo de ser executado (TCRP, 2003). Nesse sentido, a aplicação de medidas mais simples e de baixo investimento podem ter potencial para engajar os funcionários a mudarem seu padrão de viagens diário.

\section{- Estados Unidos}

Segundo Cervero (1995), nos anos 80, a maioria das metrópoles norte-americanas criou programas de caronas para os trabalhadores, agrupando-os em carros, vans e ônibus. O autor afirma que neste período, algumas empresas já encontravam dificuldades em relação à mobilidade de seus funcionários e muitas iniciaram a aplicação de programas de mobilidade corporativa de forma voluntária, já que esses problemas de mobilidade começaram a interferir em novas contratações ou mesmo em retenção de talentos em empresas localizadas em regiões com dificuldades para a locomoção. Porém, ele mostra através de levantamento bibliográfico que programas voluntários não foram suficientes para ganhar atenção de outras empresas.

Em meados dos anos 1990 o objetivo dessas políticas se ampliou e, além da redução do número de viagens, buscou-se reduzir as emissões de gases poluentes em atendimento ao Clear Air Act, legislação ambiental de abragência nacional.

A maior parte dos TROs (Trip reduction ordinances) nos Estados Unidos possui uma penalidade para o caso de não cumprimento das exigências. Comumente, a penalidade é uma taxa a ser paga pela empresa baseada na quantidade de dias de descumprimento. No entanto, na maioria dos casos não se chega a fazer uso dessas medidas. Embora seja útil ter uma ferramenta de punição caso necessário, a maioria dos órgãos prefere trabalhar junto às empresas de modo a ajudá-las a garantir o cumprimento do plano traçado ao invés de aplicar multas (ABC, 2014).

Um ponto que merece destaque na bibliografia pesquisada refere-se à redução de impostos. Uma vez implementado o plano de mobilidade corporativa nos EUA, tanto a empresa em questão como os funcionários recebem benefícios fiscais, não sendo taxados sobre o valor do benefício de transporte concedido de acordo com a TRO (ABC, 2014).

Como exemplo de medida adotada por estabelecimento da TRO, na cidade de Los Angeles as empresas devem ter planos que estabeleçam a taxa de ocupação dos veículos (TOV) de acordo com a localização da empresa na cidade (Los Angeles, 2016).

Para aumentar a efetividade das TROs, os municípios norte-americanos costumam atuar de maneira colaborativa com os empregadores. A cidade de Maricopa, no estado americano do 
Arizona, disponibiliza treinamentos gratuitos aos membros do comitê estabelecido para a montagem do PMC nas empresas, onde tratam sobre o Plano de Mobilidade Anual, a pesquisa anual do PMC a ser realizada internamente na companhia, a implementação do plano, dicas para incentivar a participação dos funcionários e a organização da documentação a ser preparada para a auditoria do governo (TCRP, 2003).

A cidade de São Francisco, na Califórnia, foi a primeira a estabelecer em 1973 limitações do uso de vias públicas e calçadas por meio de políticas públicas com estímulos à circulação de pedestres, ciclistas e à utilização de transporte público (ABC, 2014). Na cidade, essas medidas devem ser adotadas pelas empresas com mais de 20 funcionários, independentemente do local onde estejam localizadas e desempenhem suas funções. São concedidos alguns benefícios a empresa dependendo da medida adotada. As empresas oferecem ao empregado um transporte ao trabalho sem custo nenhum, através de vans ou ônibus, e contam ainda com um programa de volta garantida para casa, com sistema de caronas e bicicletas compartilhadas oferecido pela cidade. A cidade realiza pesquisas de avaliação para ajudar as empresas a escolher as medidas mais adequadas para implementação, por meio de cursos e reuniões com especialistas.

- Londres

A taxa de congestionamento (Congestion Charge) aplicada em Londres no ano de 2003 consiste em um sistema semelhante ao de pedágio para acesso à região central cidade. A taxação ocorre entre as 6 e as 18 horas em dias úteis, na região conhecida como "Centro Comercial e Financeiro de Londres", e abrange uma área de aproximadamente $12 \mathrm{~km}^{2}$. Nesse sistema, carros e caminhões devem pagar determinado valor por dia para acessar ou dirigir na zona tarifada. Táxis ficam isentos da tarifação desde que possuam certificado de veículo de baixa emissão de carbono, e os residentes registrados pagam o correspondente a um décimo do valor da tarifa (TFL, 2017a). 0 sistema conta com cerca de 1360 câmeras que automaticamente verificam a entrada dos veículos em regiões determinadas (Seattle, 2008).

Nos primeiros anos de vigência, o sistema foi considerado um excelente redutor de tráfego. A velocidade média de carros e ônibus aumentou entre $15 \%$ e $20 \%$, e os atrasos devido a congestionamentos diminuíram em 30\% (TFL, 2017b).

Contudo, esses bons resultados alcançados foram reduzindo com o passar do tempo. Segundo o Transport for London (TFL, 2017b), o motivo principal da redução dos resultados decorre de uma série de intervenções de tráfego realizadas nas ruas da área, reduzindo a capacidade de escoamento da rede viária. Essas intervenções incluíram: políticas para aumento de segurança no trânsito, melhorias urbanísticas e priorização ao transporte público, de pedestres e bicicletas, bem 
como um grande aumento de obras (TFL, 2012).

Estudo realizado em 2017 pelo ITP (2017) faz recomendações de ações para minimizar o congestionamento em Londres, como mudança no uso e ocupação do solo, priorização para transporte público, gerenciamento do transporte de carga, regulação dos táxis, nova política de estacionamento, entre outras ações. As políticas visam melhorar a qualidade de vida da população reduzindo o tempo em congestionamentos através de maior investimento e priorização do transporte público, promoção dos modos de viagem ativos e apoiar a ideia de ruas saudáveis. Essas políticas visam melhorar a mobilidade, principalmente na região central da cidade que sofre com o congestionamento.

No estudo destacam que um uso eficiente da via deve incluir espaço para caminhada, bicicletas e transporte público no lugar de carros com baixa ocupação. Entre as medidas propostas está a definição do número máximo de licenças para carros de locação e incentivo das entregas de carga no período noturno. Em relação aos pedágios urbanos, é proposto uma política de preços variáveis visando uma melhora na qualidade do ar e na redução do congestionamento.

\section{- Bélgica}

Em um estudo realizado por Malderen et. al. (2012), foi mostrado que as características da empresa influenciam na escolha da melhor maneira de promover o transporte ativo. A promoção do ciclismo é mais apropriada para pequenos locais de trabalho, já locais de trabalho maiores ou localizados em áreas centrais são mais adequados para a promoção do transporte público. Para incentivar essas medidas podem ser necessários incentivos financeiros, fornecimento de instalações, difusão de informações e gerenciamento de estacionamentos.

Os mesmos autores observaram que na Bélgica, as empresas desenvolveram uma ampla gama de iniciativas que podem ser agrupadas em duas grandes categorias: opções de viagens alternativas e medidas de atração. Foi observada também grandes diferenças entre as práticas de deslocamento dos trabalhadores nos locais de trabalho que investiram em política de mobilidade e as que não tinham políticas.

As empresas que têm uma política de mobilidade atingiram uma taxa significativamente menor de veículos com apenas uma pessoa nos locais de trabalho. As mudanças principais observadas foram para as bicicletas e carona. Já as empresas que abandonaram as políticas de mobilidade tiveram um retrocesso nos esforços que haviam alcançado.

- Austrália

Em 2016, Petrunoff et. al. analisaram os efeitos de plano de viagem que incentiva o transporte ativo no local de trabalho durante três anos. As estratégias para incentivar viagens ativas 
foram parcialmente implementadas, pois não foram implantadas estratégias para desencorajar a utilização de veículos particulares e nem algumas estratégias para sustentar as mudanças.

Foram implementadas medidas como instalação de bicicletários, acesso a vestiários com chuveiro para todos os funcionários, passeios ciclísticos no almoço e campanhas de engajamento. Mesmo sem ter o plano implantado em sua totalidade, foi observada que a proporção de funcionários que viajam ativamente para o trabalho aumentou entre $4 \%$ e $6 \%$ nos anos de intervenção em comparação com a linha de base.

\section{PROPOSTAS PARA O BRASIL}

O sucesso alcançado com os planos de mobilidade corporativa adotados em outros locais demonstra um potencial no Brasil para realização de parcerias entre os governos federal, estadual e municipal e os empregadores no combate aos congestionamentos e redução de impactos ambientais.

No Brasil, algumas medidas de gestão da demanda de viagens já são aplicadas. É o caso do "Programa de Restrição ao Trânsito de Veículos Automotores no Município de São Paulo", o qual limita a circulação de veículos de acordo com sua placa, ferramenta utilizada em São Paulo desde 1997 (SÃO PAULO, 1997). Outro exemplo é a cobrança pelo estacionamento de veículos em vias públicas nos centros urbanos com o objetivo de desestimular a opção pelo transporte individual motorizado. A Lei $6.002 / 87$ de Porto Alegre foi a primeira a implantar esta medida no Brasil (PORTO ALEGRE, 1987). Porém, para a mitigação dos problemas de mobilidade enfrentados essas medidas não são suficientes. É necessário englobar outras medidas às já praticadas para atingir os níveis desejáveis de melhorias na mobilidade.

Há registros de empresas que já implementaram a utilização de um Plano de Mobilidade Corporativa de maneira proativa, mesmo sem a existência de uma legislação que as obrigue a tomada de tal medida.

Em 2012, uma parceria entre o Banco Mundial (BIRD), o World Resources Institute (WRI) e Embarq Brasil deu origem ao "Projeto Piloto de Mobilidade Corporativa CENU-WTC", com intuito de envolver o setor privado na melhoria da mobilidade na cidade de São Paulo. O projeto foi pioneiro no Brasil ao elaborar um plano de mobilidade com foco no papel dos empregadores.

Nos resultados apresentados pelo The City Fix Brasil (2013), os principais fatores para o sucesso foram o apoio da direção, esforços do Coordenador de Mobilidade e os incentivos e desincentivos financeiros. O comprometimento do empregador, com a participação da direção da 
empresa, foi apontado como fator primordial para o sucesso do PMC. Como lição, os especialistas relatam que é fundamental que empregadores e empregados conheçam as diversas alternativas, e sejam incentivados a usá-las (DECASTRO, 2014).

Com o engajamento dos empregadores na criação e promoção de políticas de viagens de seus funcionários, o governo estaria dando soluções ao problema em questão (extensos congestionamentos nos horários de pico) atingindo sua causa mais expressiva (viagens de deslocamento casa-trabalho-casa).

As empresas possuem o potencial de obter dados de deslocamento dos seus funcionários de forma relativamente simples. Esta pode ser uma ferramenta bastante útil na gestão dos deslocamentos nos centros urbanos, com base em dados precisos de horários de chegada e saída, origem e destino, tempo no trajeto, dentre outros. Dessa forma, as pesquisas de padrões de deslocamento, do tipo origem-destino (O-D), extremamente complexas de serem realizadas principalmente em megacidades, além de serem custosas ao estado, seriam evitadas, além de se poder obter esses dados com mais frequência, possibilitando ainda o acompanhamento de tendências históricas.

\subsection{Proposta de Plano de Mobilidade Corporativa}

Com base na bibliografia pesquisada, segue-se com os principais pontos identificados com potencial de aplicação no Brasil.

\section{- Teletrabalho}

O teletrabalho permite melhorias em aspectos econômicos, com a redução de alguns custos associados à manutenção da totalidade dos funcionários em um ambiente corporativo. Há posições nas empresas que não requerem a presença do funcionário no escritório. Rocha et al (2006) estima que utilizando o teletrabalho duas vezes por semana, reduz-se o número de deslocamentos em $40 \%$.

Vale destacar a necessidade de realizar mudanças culturais nas organizações. Ressalta-se que este tipo de trabalho flexível é extensivo a um número limitado de participantes. Pode ser necessário que pessoas que lidam com documentos e informações confidenciais realizem treinamentos antes de aderir esta forma de trabalho flexível, visando evitar que estas informações venham a ser difundidas sem intenção.

É importante fazer uso da tecnologia a favor deste processo. Muitas vezes a presença física de algumas pessoas é dispensável, dada a possibilidade de realização de videoconferências, por exemplo. Estima-se que até $50 \%$ de todos os tipos de trabalho sejam apropriados para o teletrabalho (ROCHA et. al., 2006). 
O teletrabalho ainda é uma prática recente no Brasil. Em 2016, 60\% das empresas que faziam uso deste recurso praticavam entre 1 e 5 anos; 20\% havia menos de 1 ano e os outros $20 \%$ acima de 5 anos (SAP CONSULTORIA, 2016).

No Brasil, ainda é pequena a parcela dos funcionários de empresas com esse perfil, a maioria concentrada na região sudeste. Com o avanço da tecnologia e o incentivo do governo, este número tende a aumentar. $89 \%$ das empresas que fazem uso do home office no Brasil relatam que a estratégia aumenta a atração de colaboradores para a empresa; $85 \%$ declaram ser benéfico à retenção de talentos (SAP CONSULTORIA, 2016). Algumas empresas relatam dificuldades em relação à prática do teletrabalho, sendo os principais riscos associados à legislação (Figura 2). Mesmo assim, já é possível encontrar até mesmo órgãos públicos que fazem uso do teletrabalho. Importante destacar que esse tipo de medida tende a ser aprimorado após a pandemia ocorria nos anos de 2020 e 2021, tendo muitas empresas determinado que manterão por determinados dias da semana o trabalho remoto de forma permanente.

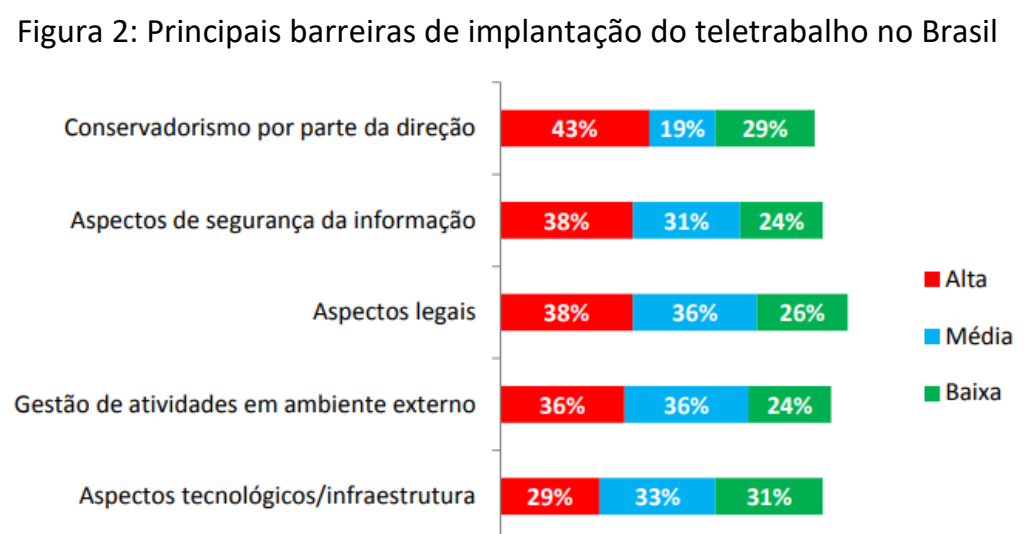

Fonte: SAP Consultoria (2016).

\section{- Carona solidária}

Esta medida pode ser desenvolvida com certa facilidade nas empresas. Através do PMC, com o mapeamento dos fluxos de pessoas que se deslocam até o trabalho, o empregador consegue ter a noção exata do panorama que os funcionários enfrentam diariamente até chegar ao trabalho.

Empresas podem incentivar seus funcionários a oferecerem e receberem caronas utilizando a intranet da empresa. Tem-se também a facilidade dos aplicativos de carona para celular, nos quais o usuário pode agendar seus horários e verificar a disponibilidade de caronas oferecidas na região onde reside, além de realizar pagamentos por meio do aplicativo. Medidas simples como reservar vagas de estacionamento exclusivamente para carros com caronas podem ser aplicadas. Empresas que possuem carros de frota podem limitar o uso a funcionários que ofereçam carona aos colegas de trabalho. 
Especialmente para funcionários que possuem horários fixos de entrada e saída, a carona é uma maneira de locomoção, além de promover uma interação entre funcionários de diferentes departamentos.

- Caminhada e ciclismo

A Figura 3 demonstra a distribuição da malha ciclo viária brasileira. É possível constatar que apenas 3 cidades concentram grande parte da malha do país, demonstrando que ainda são poucas as regiões servidas por ciclovias. Para adoção de um PMC que incentive a pedalada, não se deve esquecer a instalação de bicicletários. Para proporcionar uma comodidade ao funcionário, sugerese investir em uma infraestrutura mínima de vestiário e armários, além de disponibilizar acessórios de reparos básicos para bicicleta.

Caminhadas e pedaladas são atividades que, além de serem benéficas à saúde e qualidade de vida do indivíduo que pratica evita que mais um carro esteja nas ruas impactando nos engarrafamentos. Em países como Alemanha, Bélgica e Holanda as ciclovias foram construídas de forma a possibilitar o percurso por bicicleta por distâncias mais longas do que as praticadas hoje no Brasil. Entende-se que este modo deveria ser incentivado a um grupo restrito de funcionários, que residam entre 3 e 5 quilômetros dos locais de trabalho. As condições do entorno da empresa devem ser observadas visando evitar possíveis acidentes de trânsito.

Figura 3: Estrutura ciclo viária em cidades do Brasil (km)

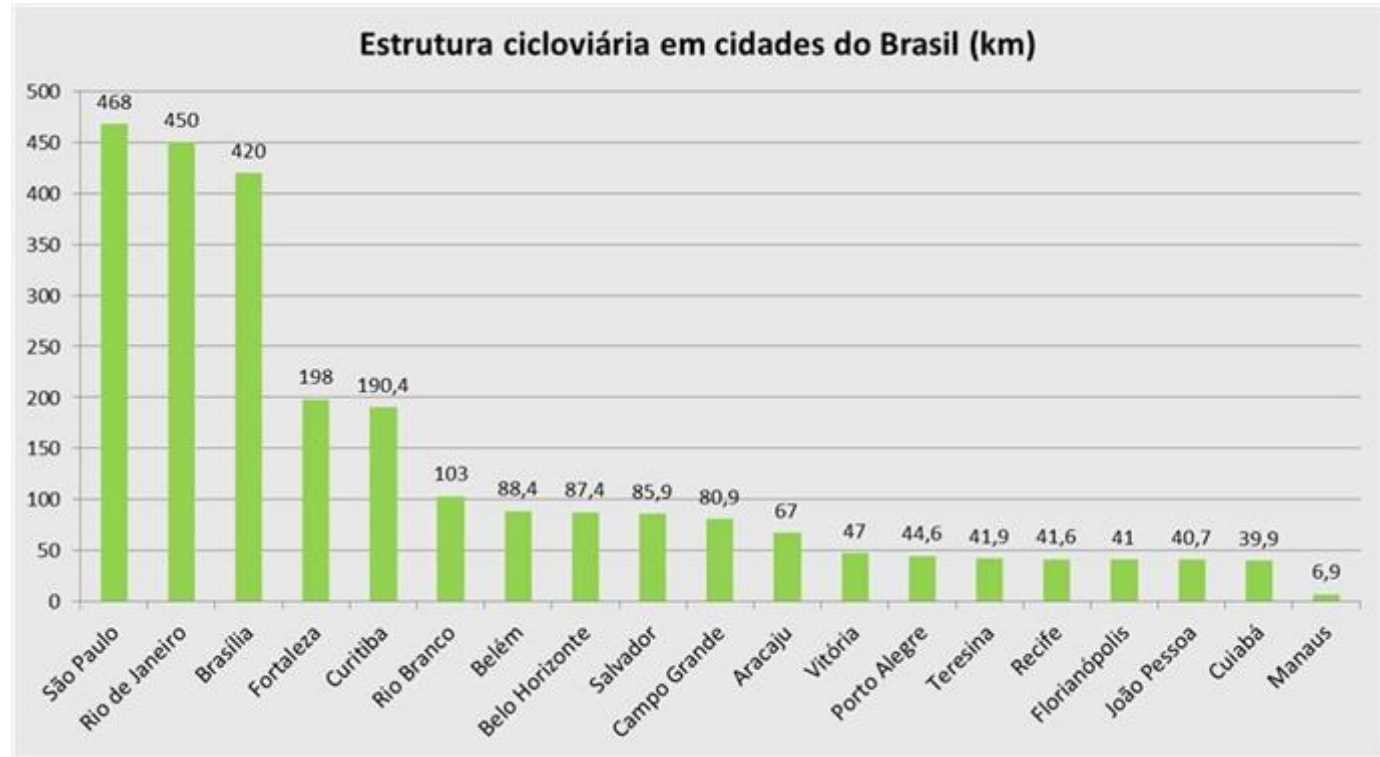

Fonte: Mobilize (2017).

- Transporte público

O transporte público deve ser amplamente incentivado por parte dos empregadores como modo de transporte. A experiência observada em países europeus nos mostra que muito embora seja de alta complexidade e haja resistência, a mudança cultural envolvida para opção por modos 
de transporte coletivos traz benefícios a toda a população. É imprescindível que as empresas atuem junto ao poder público para garantir que a rede de transportes públicos seja devidamente ampliada, a exemplo dos corredores e faixas exclusivas para; redução de headways entre composições de metrôs e trens em horários de pico; entre outros. Além disso, faz-se necessário que as empresas atuem junto ao poder público em busca de mais segurança e qualidade, maior oferta de ônibus, além da indispensável previsibilidade.

A isenção do desconto do vale transporte aumenta ainda mais o potencial de aumento da opção pelo transporte público e redução do uso de automóveis pelos funcionários (WRI CIDADES, 2017).

Importante destacar que a rede deve ser constantemente atualizada com o uso da tecnologia a favor da comodidade do usuário, de modo a garantir a constante opção por este meio de transporte.

\section{- Atrações alternativas para evitar horários de pico}

Outra boa capacidade encontrada refere-se à utilização do espaço de trabalho como um atrativo para que o funcionário se desloque para casa fora dos horários de pico. A criação de espaços para leitura, salas com televisões e lanchonetes são sugestões ao que pode ser implementado, assim como academias e espaços de terapias e massagens.

Como contribuição à realidade atual brasileira, as Figuras 4 e 5 apresentam as principais medidas encontradas cabíveis de aplicação em planos de mobilidade corporativa, considerando-se a cultura organizacional mais comumente encontrada no país. Salienta-se algumas das vantagens e os principais aspectos limitadores em se adotar tais medidas no Brasil.

Similarmente, as Tabelas 1 e 2 explicitam as principais vantagens e limitações em transformar os planos descritos acima em políticas públicas geridas pelo estado. Deve-se compreender e respeitar as diferenças sociais, econômicas e culturais existentes entre as diferentes cidades abordadas, e nesse sentido limites não devem ser ultrapassados.

Com a consolidação das principais medidas para a criação de PMC e políticas públicas do tipo TROs, pode-se perceber que existe grande potencial ainda incipiente no Brasil. As maiores dificuldades encontradas estão relacionadas a legislações e apoio do governo federal, estadual e municipal na atualização de leis que muitas vezes não abordam a tecnologia do mundo globalizado. 
Tabela 1: Medidas de PMC com potencial de implementação no Brasil - Ações do Empregador

\begin{tabular}{|c|c|c|c|c|c|}
\hline \multirow[t]{2}{*}{ Medida } & \multicolumn{2}{|c|}{$\begin{array}{l}\text { Aplicação } \\
\text { cidades } \\
\text { avaliadas }\end{array}$} & \multirow[t]{2}{*}{ Principais Vantagens } & \multirow[t]{2}{*}{$\begin{array}{c}\text { Principais Dificuldades / } \\
\text { Limitações }\end{array}$} & \multirow[t]{2}{*}{$\begin{array}{c}\text { Aplicação no } \\
\text { Brasil (1) }\end{array}$} \\
\hline & EUA & Europa & & & \\
\hline \multirow{3}{*}{$\begin{array}{l}\text { Sistema de } \\
\text { Carona }\end{array}$} & \multirow{3}{*}{$X$} & \multirow{3}{*}{$X$} & \multirow{3}{*}{$\begin{array}{l}\text { - Uso de softwares e aplicativos já } \\
\text { disponíveis; } \\
\text { - Redução de viagens em } \\
\text { automóveis; } \\
\text { - Interação benéfica entre } \\
\text { funcionários }\end{array}$} & $\begin{array}{l}\text { Horários fixos de entrada e } \\
\text { saída }\end{array}$ & \multirow{3}{*}{ Aplicável } \\
\hline & & & & $\begin{array}{l}\text { Possível necessidade de } \\
\text { transporte especial }\end{array}$ & \\
\hline & & & & $\begin{array}{l}\text { Decisão pessoal do } \\
\text { funcionário sobre carona } \\
\text { com desconhecido }\end{array}$ & \\
\hline \multirow{6}{*}{ Teletrabalho } & \multirow{6}{*}{$X$} & \multirow{6}{*}{$\mathrm{X}$} & \multirow{6}{*}{$\begin{array}{l}\text { - Redução de custos: } \\
\text { - Empresa (infra., } \\
\text { estacionamento) } \\
\text { - Funcionário (combustível, } \\
\text { manut. } \\
\text { carro, estacionamento) } \\
\text { - Satisfação e engajamento de } \\
\text { colaboradores; } \\
\text { - Tecnologia já existente; } \\
\text { - Atração de novos colaboradores } \\
\text { e retenção de talentos; } \\
\text { - Aumento do bem estar e } \\
\text { qualidade de vida (redução de } \\
\text { estresse e perda de tempo com } \\
\text { congestionamentos); } \\
\text { - Ganhos ambientais (reduz } \\
\text { emissão GEEs) }\end{array}$} & $\begin{array}{l}\text { Aspectos legais (Legislação } \\
\text { trabalhista) }\end{array}$ & \multirow{6}{*}{$\begin{array}{l}\text { Aplicável, com } \\
\text { restricões (2) }\end{array}$} \\
\hline & & & & $\begin{array}{l}\text { Aspectos tecnológicos/infra. } \\
\text { - adequação infra. de casa p/ } \\
\text { ambiente de trabalho }\end{array}$ & \\
\hline & & & & $\begin{array}{l}\text { Elegibilidade: } \\
\text { - Escopo da função; } \\
\text { - Aceitação do colaborador; } \\
\text { - Aceitação do superior } \\
\text { imediato }\end{array}$ & \\
\hline & & & & $\begin{array}{l}\text { Mudanças culturais e } \\
\text { organizacionais na empresa }\end{array}$ & \\
\hline & & & & $\begin{array}{l}\text { Aspectos de segurança da } \\
\text { informação }\end{array}$ & \\
\hline & & & & $\begin{array}{l}\text { Gestão de atividades em } \\
\text { ambiente externo }\end{array}$ & \\
\hline \multirow{4}{*}{$\begin{array}{l}\text { Transporte } \\
\text { não } \\
\text { motorizado }\end{array}$} & \multirow[t]{4}{*}{$X$} & \multirow[t]{4}{*}{$\mathrm{x}$} & \multirow{4}{*}{$\begin{array}{l}\text { - Benefícios à saúde e qualidade de } \\
\text { vida dos funcionários; } \\
\text { - Interação entre colegas de } \\
\text { trabalho; } \\
\text { - Ganhos ambientais - redução da } \\
\text { emissão de GEEs; } \\
\text { - Promover imagem sustentável da } \\
\text { empresa }\end{array}$} & $\begin{array}{l}\text { Infraestrutura viária mínima } \\
\text { (calçadas, ciclofaixas, } \\
\text { ciclovias, passarelas, } \\
\text { acessibilidade) }\end{array}$ & \multirow{4}{*}{$\begin{array}{l}\text { Aplicável, com } \\
\text { apoio do } \\
\text { poder público } \\
\text { (3) }\end{array}$} \\
\hline & & & & $\begin{array}{l}\text { Necessária atuação da } \\
\text { empresa junto à prefeitura } \\
\text { (região do entorno) }\end{array}$ & \\
\hline & & & & $\begin{array}{l}\text { Residências próximas ao } \\
\text { local de trabalho ( } 3 \text { a } 5 \text { km) }\end{array}$ & \\
\hline & & & & $\begin{array}{l}\text { Infraestrutura mínima na } \\
\text { empresa (bicicletário, } \\
\text { vestiário) }\end{array}$ & \\
\hline
\end{tabular}

(continua) 
(continuação)

\begin{tabular}{|c|c|c|c|c|c|}
\hline \multirow[t]{2}{*}{ Medida } & \multicolumn{2}{|c|}{$\begin{array}{l}\text { Aplicação } \\
\text { cidades } \\
\text { avaliadas }\end{array}$} & \multirow[t]{2}{*}{ Principais Vantagens } & \multirow[t]{2}{*}{$\begin{array}{c}\text { Principais Dificuldades / } \\
\text { Limitações }\end{array}$} & \multirow[t]{2}{*}{$\begin{array}{c}\text { Aplicação no } \\
\text { Brasil (1) }\end{array}$} \\
\hline & EUA & Europa & & & \\
\hline $\begin{array}{c}\text { Transporte } \\
\text { público / } \\
\text { ônibus fretado }\end{array}$ & $x$ & $x$ & $\begin{array}{l}\text { - Redução de viagens em } \\
\text { automóveis; } \\
\text { - Redução de custos } \\
\text { - Empresa: infraestrutura, } \\
\text { energia, estacionamento, } \\
\text { deslocamento, ... } \\
\text { - Funcionário: redução de } \\
\text { gastos com combustível e } \\
\text { manutenção do carro; } \\
\text { estacionamento; } \\
\text { - Ganhos ambientais - redução } \\
\text { da emissão de GEEs }\end{array}$ & $\begin{array}{l}\text { Baixa qualidade do transporte } \\
\text { público (difícil adesão do } \\
\text { funcionário) } \\
\text { Atuação da empresa junto à } \\
\text { prefeitura para melhorias na } \\
\text { oferta de transporte público da } \\
\text { cidade (ganhos a toda a } \\
\text { comunidade) }\end{array}$ & $\begin{array}{l}\text { Aplicável, com } \\
\text { apoio do } \\
\text { poder público } \\
\text { (4) }\end{array}$ \\
\hline
\end{tabular}

(1) Refere-se às possibilidades de aplicar as referidas medidas nas cidades brasileiras, em geral, a curto/médio prazo, na época de elaboração deste estudo.

(2) Devem ser observadas as funções que permitem este tipo de aplicação de trabalho, realizando treinamentos. Com a legislação atual, empresa deverá realizar inspeções no local de teletrabalho.

(3) Deve haver inspeção nos entornos do local de trabalho, observando as condições de acessibilidade.

(4) Essencial atuação das empresas junto aos órgãos de transportes, bem como a participação social - deve ocorrer de forma colaborativa. Sugere-se a criação de uma organização específica para confrontar os interesses e garantir o alcance dos benefícios almejados.

Tabela 2: Políticas públicas de mobilidade corporativa com potencial de implementação no Brasil - Regulamentação de Redução de Viagens - Políticas Públicas

\begin{tabular}{|c|c|c|c|c|c|}
\hline \multirow[t]{2}{*}{ Medida } & \multicolumn{2}{|c|}{$\begin{array}{l}\text { Aplicação nas } \\
\text { cidades } \\
\text { avaliadas }\end{array}$} & \multirow[t]{2}{*}{ Principais Vantagens } & \multirow[t]{2}{*}{ Principais Desafios / Limitações } & \multirow{2}{*}{$\begin{array}{l}\text { Aplicação } \\
\text { no Brasil } \\
\text { (1) }\end{array}$} \\
\hline & EUA & Europa & & & \\
\hline \multirow[t]{2}{*}{$\begin{array}{l}\text { Campanhas de } \\
\text { conscientização } \\
\text { sobre viagens }\end{array}$} & $\mathrm{X}$ & $\mathrm{X}$ & $\begin{array}{l}\text { - Publicidade: conscientizar } \\
\text { não só funcionários, como } \\
\text { a população; } \\
\text { - "Dia mundial sem carro": } \\
\text { adesão de toda população, } \\
\text { destacando a importância } \\
\text { do uso de alternativas ao } \\
\text { automóvel para a } \\
\text { mobilidade }\end{array}$ & $\begin{array}{l}\text { - Gastos com publicidade } \\
\text { - Necessário divulgar ações e } \\
\text { resultados encontrados para obter } \\
\text { mais adesões (efetividade da } \\
\text { política) } \\
\text { - Uso de páginas oficiais do } \\
\text { governo como forma de } \\
\text { divulgação }\end{array}$ & Existente \\
\hline & & & & $\begin{array}{l}\text { - Redução de receita do município, } \\
\text { sem a comprovação efetiva dos } \\
\text { demais ganhos a médio / longo } \\
\text { prazo }\end{array}$ & \\
\hline $\begin{array}{c}\text { Canal de } \\
\text { comunicação } \\
\text { entre poder } \\
\text { público, } \\
\text { empregador e } \\
\text { população }\end{array}$ & $\mathrm{X}$ & $\mathrm{X}$ & $\begin{array}{l}\text { - Centralização das } \\
\text { informações em um } \\
\text { ambiente único e exclusivo } \\
\text { para este fim; } \\
\text { - Utilização de estrutura de } \\
\text { tecnologia existente } \\
\text { (sistemas e sites oficiais da } \\
\text { prefeitura) }\end{array}$ & $\begin{array}{l}\text { - Necessidade de criar organização } \\
\text { focada em consolidar direitos, } \\
\text { deveres e interesses das partes } \\
\text { envolvidas }\end{array}$ & $\begin{array}{l}\text { Existente - } \\
\text { necessário } \\
\text { apoio da } \\
\text { prefeitura } \\
\text { local (3) }\end{array}$ \\
\hline
\end{tabular}


(continuação)

\begin{tabular}{|c|c|c|c|c|c|}
\hline \multirow[t]{2}{*}{ Medida } & \multicolumn{2}{|c|}{$\begin{array}{l}\text { Aplicação nas } \\
\text { cidades } \\
\text { avaliadas }\end{array}$} & \multirow[t]{2}{*}{ Principais Vantagens } & \multirow[t]{2}{*}{ Principais Desafios / Limitações } & \multirow[t]{2}{*}{$\begin{array}{c}\text { Aplicação } \\
\text { no Brasil (1) }\end{array}$} \\
\hline & EUA & Europa & & & \\
\hline $\begin{array}{c}\text { Treinamentos ao } \\
\text { empregador }\end{array}$ & $X$ & & $\begin{array}{l}\text { - Garantia de que toda } \\
\text { empresa elegível (de } \\
\text { acordo com os critérios de } \\
\text { obrigatoriedade } \\
\text { estabelecidos): } \\
\quad \text { - detenham o } \\
\text { conhecimento para realizar } \\
\text { planos de mobilidade } \\
\text { corporativa; } \\
\quad \text { - recorram em caso de } \\
\text { dúvidas no processo, } \\
\text { sempre que necessário }\end{array}$ & $\begin{array}{l}\text { - Necessidade de estabelecer uma } \\
\text { organização focada em consolidar } \\
\text { direitos, deveres e interesses das } \\
\text { partes envolvidas }\end{array}$ & $\begin{array}{l}\text { Não } \\
\text { Existente - } \\
\text { necessários } \\
\text { maiores } \\
\text { estudos (4) }\end{array}$ \\
\hline $\begin{array}{l}\text { Legislação } \\
\text { trabalhista } \\
\text { abrangendo o } \\
\text { teletrabalho }\end{array}$ & & $\mathrm{X}$ & $\begin{array}{l}\text { - Segurança aos } \\
\text { funcionários; } \\
\text { - Condições adequadas de } \\
\text { infraestrutura para } \\
\text { trabalho à distância; } \\
\text { - Alterações recentes nas } \\
\text { leis trabalhistas podem } \\
\text { ajudar na concepção desta } \\
\text { forma de trabalho }\end{array}$ & $\begin{array}{l}\text { - Prováveis dificuldades em obter } \\
\text { apoio para mudanças em } \\
\text { legislações a curto / médio prazo }\end{array}$ & $\begin{array}{l}\text { Não } \\
\text { Existente - } \\
\text { necessário } \\
\text { apoio do } \\
\text { poder } \\
\text { público (5) }\end{array}$ \\
\hline $\begin{array}{l}\text { Criação da } \\
\text { Política Pública } \\
\text { (estabelecer } \\
\text { requisitos e } \\
\text { penalidades às } \\
\text { empresas) }\end{array}$ & $x$ & $\mathrm{x}$ & $\begin{array}{l}\text { - Maior engajamento dos } \\
\text { empregadores em } \\
\text { estimular mudanças nos } \\
\text { padrões de viagens dos } \\
\text { funcionários; } \\
\text { - Tornar a prática comum } \\
\text { entre empresas de } \\
\text { diversos segmentos e } \\
\text { portes; } \\
\text { - Estimular a parceria entre } \\
\text { empresas localizadas em } \\
\text { centros comerciais } \\
\text { próximos; } \\
\text { - Controle da qualidade do } \\
\text { ar em áreas urbanas; } \\
\text { - Reafirmação de } \\
\text { compromissos de } \\
\text { sustentabilidade }\end{array}$ & $\begin{array}{l}\text { - Possíveis dificuldades em obter } \\
\text { apoio dos municípios para } \\
\text { mudanças em legislações a curto / } \\
\text { médio prazo }\end{array}$ & $\begin{array}{l}\text { Não } \\
\text { Existente - } \\
\text { necessário } \\
\text { apoio do } \\
\text { poder } \\
\text { público (6) }\end{array}$ \\
\hline
\end{tabular}

(continua) 
(continuação)

\begin{tabular}{|c|c|c|c|c|c|}
\hline \multirow[t]{2}{*}{ Medida } & \multicolumn{2}{|c|}{$\begin{array}{c}\text { Aplicação nas } \\
\text { cidades } \\
\text { avaliadas }\end{array}$} & \multirow[t]{2}{*}{ Principais Vantagens } & \multirow[t]{2}{*}{ Principais Desafios / Limitações } & \multirow[t]{2}{*}{$\begin{array}{c}\text { Aplicação } \\
\text { no Brasil (1) }\end{array}$} \\
\hline & EUA & Europa & & & \\
\hline $\begin{array}{c}\text { Estabelecer } \\
\text { rotina de retorno } \\
\text { das informações } \\
\text { ao Poder Público } \\
\text { (feedback) }\end{array}$ & $x$ & $\mathrm{X}$ & $\begin{array}{l}\text { - Informações de } \\
\text { deslocamentos de grandes } \\
\text { massas populacionais pela } \\
\text { cidade diariamente } \\
\text { - Economia em pesquisas } \\
\text { domiciliares (O-D) aos } \\
\text { cofres públicos } \\
\text { - Melhoria contínua de } \\
\text { inovações trazidas pelo } \\
\text { empregador }\end{array}$ & $\begin{array}{l}\text { - Estabelecimento de um } \\
\text { documento padrão, para evitar } \\
\text { retrabalho e impossibilidade de } \\
\text { consolidação das informações } \\
\text { - Garantir correto tratamento dos } \\
\text { dados recebidos (armazenagem, } \\
\text { controle e uso - grande volume de } \\
\text { dados - big data) } \\
\text { - Conciliar particularidades de } \\
\text { cada empresa, de acordo com a } \\
\text { sazonalidade de viagens realizadas }\end{array}$ & $\begin{array}{l}\text { Não } \\
\text { Existente - } \\
\text { necessário } \\
\text { apoio do } \\
\text { poder } \\
\text { público (7) }\end{array}$ \\
\hline $\begin{array}{l}\text { Organização da } \\
\text { articulação entre } \\
\text { atores públicos e } \\
\text { privados }\end{array}$ & $x$ & $x$ & $\begin{array}{l}\text { - Mapeamento da situação } \\
\text { real dos deslocamentos na } \\
\text { cidade; } \\
\text { - Uso dos dados obtidos } \\
\text { para atrair mais empresas } \\
\text { à adesão (percentual de } \\
\text { redução de custos e } \\
\text { redução de gases } \\
\text { poluentes gerados por ano, } \\
\text { por exemplo) } \\
\text { - Participação proativa de } \\
\text { empresas não obrigatórias } \\
\text { pela política, através da } \\
\text { comprovação dos } \\
\text { resultados esperados }\end{array}$ & $\begin{array}{l}\text { - Necessidade de criar organização } \\
\text { para receber e organizar (ou } \\
\text { repassar ao órgão ou empresa } \\
\text { responsável) o produto final } \\
\text { gerado com os dados das } \\
\text { empresas e dos funcionários }\end{array}$ & $\begin{array}{l}\text { Existente - } \\
\text { necessário } \\
\text { apoio da } \\
\text { prefeitura } \\
\text { local (3) }\end{array}$ \\
\hline
\end{tabular}

(1) Refere-se as possibilidades de aplicar as referidas medidas nas cidades brasileiras, em geral a curto prazo, na época de elaboração deste estudo.

(2) Incentivos ficais requerem não apenas apoio do governo, como estudos mais apurados de viabilidade da implantação e retorno da medida tomada. Necessário comprovar os ganhos que serão obtidos (ambientais, econômicos e sociais).

(3) Necessário que a Prefeitura da cidade esteja disposta a comprometer-se com a causa, dispondo de recursos próprios para implementação da política pública.

(4) A curto prazo, para não inviabilizar a prática das medidas propostas, seriam necessários mais estudos e orçamento disponível para tal.

(5) Apesar de não abranger o teletrabalho, também não há restrições na legislação trabalhista que impeçam o funcionário a realizar teletrabalho, seja meio período, em regime de escala ou full time.

(6) Necessário que haja vontade política com atuação e apoio conjunto entre poder público, instituições privadas e população para efetiva implementação de regulamentações acerca do tema.

(7) Necessária infraestrutura e pessoas capacitadas para desempenhar a função de reunir e divulgar os dados obtidos.

\section{CONCLUSÕES}

Este trabalho teve como objetivo explorar as soluções de mobilidade corporativa que vêm sendo empregadas em grandes cidades do mundo, e obter informações de como vincular à realidade brasileira. Com a reunião de conceitos de Gestão de Demanda de Viagens (GDV), mobilidade corporativa e Trip Reduction Ordinances (TROs), ainda dispersos na literatura brasileira, foi possível abordar de forma prática as opções de aplicação no Brasil.

Embora não seja um conceito novo, a Gestão de Demanda de Viagens ainda é uma 
ferramenta pouco difundida nas cidades brasileiras, porém com enorme potencial de alcance a melhorias nos congestionamentos. GDV trata essencialmente de utilizar a infraestrutura e os serviços de transporte já existentes de maneira mais eficiente, realizando mudanças no padrão de viagens dos usuários. O gerenciamento das viagens torna-se ainda mais necessário tendo em vista as lacunas de investimentos em infraestrutura viária que permaneceram durante anos no Brasil.

Os desafios existentes para a aplicação das medidas propostas são evidentes; é necessário haver engajamento do poder público e vontade política para a utilização da mobilidade corporativa como uma ferramenta de GDV. Ressalta-se a necessidade de compatibilização das medidas propostas em cada cidade de acordo com as legislações municipais vigentes.

Notou-se que em diversos documentos oficiais, as esferas do governo citam a falta de comunicação entre órgãos federais, estaduais e municipais como um grande complicador na aplicação de políticas pública. Para a eficácia das políticas sugeridas neste trabalho, é necessário que haja diálogo entre estes órgãos. Nesse quesito, destaca-se ser interessante a criação de uma Organização que trabalhe na articulação com os atores públicos e privados, na busca por viagens mais eficientes.

Sabe-se que muitas ações devem ser tomadas por parte dos governos e dos empregadores buscando a melhoria da mobilidade urbana, melhor uso da infraestrutura e dos serviços de transporte já disponíveis inclusive no que se refere a mudanças culturais. Espera-se que o presente trabalho possa contribuir para a integração de possíveis soluções adotadas pelo poder público e por empresas no âmbito de reduzir a demanda por viagens. É preciso adequar a cultura das empresas e educar a população sobre o impacto de cada medida. Principalmente em centros urbanos, a adoção de planos de mobilidade corporativa faria diferenças significativas nos congestionamentos diários.

É necessário começar a enxergar as empresas como as fortes detentoras de informações essenciais ao planejamento de transportes das cidades que são, tendo em vista o potencial de fornecimento destas informações de deslocamentos. Esses dados atualmente são obtidos com certa dificuldade, tendo em vista os custos associados à realização de pesquisas domiciliares, além da falta de acompanhamento histórico.

Com base nas informações coletadas, recomenda-se que em um primeiro momento, haja apoio dos municípios que constituem grandes cidades para que as grandes empresas participem ativamente de iniciativas de mobilidade corporativa, garantindo conforto, bem-estar e melhorias de toda a vizinhança do entorno.

Por fim, conclui-se que existem vastas oportunidades de implantação de políticas públicas de gestão da mobilidade corporativa no Brasil. Muito embora exista grande potencial para isto, há 
um longo percurso em relação às legislações e à forma como o processo de acompanhamento e feedback do governo deve ser conduzido posteriormente à aplicação da política pública.

O futuro da mobilidade corporativa mostra-se promissor. A chegada de modelos inovadores de transporte, como os recentes serviços de carro compartilhado (car sharing) e corrida compartilhada (ride sharing), tende a fomentar a redução do uso e propriedade individual de automóveis nas próximas décadas, acarretando o aumento da taxa de ocupação dos veículos. Além disso, decisões recentes do governo brasileiro mostram uma tendência por cada vez mais partilhar as responsabilidades com as empresas por meio de parcerias público-privadas (PPP), corroborando com implantação de políticas públicas de mobilidade corporativa.

Para trabalhos futuros, sugere-se averiguar a capacidade de implementação de uma Política de Mobilidade Corporativa em uma cidade brasileira, considerando-se uma região central de grande concentração de empresas e deslocamentos de funcionários. Outra sugestão é elaborar um plano de mobilidade corporativa em uma empresa com a utilização de um dos modelos referenciados, a fim de estimar os resultados de redução de viagens e compará-los com o encontrado na prática.

\section{REFERÊNCIAS}

ABC (2014) Establishing an effective commute trip reduction policy in Massachussets. Lessons learned from leading programs. Massachussets. Disponível em: <https://www.abettercity.org/docs/Effective\%20TRO\%20Final.pdf> Acesso em: 1 de julho de 2017.

Brasil (1988), Presidência da República. Subchefia para Assuntos Jurídicos. Constituição da República Federativa do Brasil, 5 de outubro de 1988. Brasília, DF, 1988.

Brasil (2012) Lei № 12.587, de 3 de janeiro de 2012. Brasília, 2012. Disponível em: http://www.planalto.gov.br/ccivil_03/_ato201114/2012/lei/l12587.htm\&gt;.Acesso em: 3 de maio de 2017.

CALTRANS (2016) High occupancy vehicle systems. HOV lanes. California department of transportation - DOT-CA, Califórnia. Disponível em: <http://www.dot.ca.gov/trafficops/tm/hov.html> Acesso em: 1 de agosto de 2017.

Cervero, R. An evaluation of the relationships between transit and urban form. Transit Cooperative Research Program, TCRP. Washington, $1995 . \quad$ Disponível em: <http://onlinepubs.trb.org/onlinepubs/tcrp/tcrp_rrd_07.pdf> Acesso em: 15 de Agosto 2017.

CET-SP (2017) Companhia de engenharia de tráfego da cidade de São Paulo. Rodízio municipal como funciona. São Paulo. Disponível em: <http://www.cetsp.com.br/consultas/rodiziomunicipal/como-funciona.aspx> Acesso em: 5 de agosto de 2017.

Decastro, J. (2014) Caracterização e análise do deslocamento "casa-trabalho-casa" em empresas localizadas na Barra da Tijuca - RJ. Dissertação de Mestrado do Programa de Engenharia de 
Transporte da COPPE-UFRJ. Rio de Janeiro.

Embarq Brasil (2015). Passo a Passo para a Construção de um Plano de Mobilidade Corporativa. Disponível em:

<http://www.wrirosscities.org/sites/default/files/Passo\%20a\%20Passo\%20para\%20a\%20Construo \%20de\%20um\%20Plano\%20de\%20Mobilidade\%20Corporativa\%20-\%20WRI\%20Cidades.pdf> Acesso em: 9 de maio de 2017.

EY-MOBILIZE BRASIL (2016) Guia de mobilidade corporativa: Edição 2016. Disponível em: <http://www.mobilize.org.br/midias/pesquisas/guia-de-mobilidade-corporativa-ey---mobilizebrasi.pdf> Acesso em: 10 de julho de 2017.

FIRJAN (2015) 0 custo dos deslocamentos nas principais áreas urbanas do Brasil. Rio de Janeiro. Disponível em: <http://www.firjan.com.br/publicacoes/publicacoes-de-economia/o-custo-dosdeslocamentos-nas-principais-areas-urbanas-do-brasil.htm> Acesso em: 10 de agosto de 2017.

ITP (2017). On behalf of Greater London Authority. Relatório do projeto "Understanding and Managing Congestion", Londres, Novembro de 2017.

Los Angeles (2016) Employee commute reduction program (Rideshare program). Employee transportation coordinator's manual, Los Angeles. Disponível em: $<$ http://rideshare.lacounty.gov/wp-content/uploads/2012/10/ Consolidated-ETC-Manual-rev-1Cover-4-final2016.pdf> Acesso em: 30 agosto 2017.

Malderen, L., Jourquin, B., Thomas, I., Vanoutive, T., Verhetsel, A. e Witlox, F. (2012) On the mobility policies of companies: What are the good practices? The Belgian case. Transport Policy, volume, pp. 10-19.

Ministério Das Cidades (2007) Caderno de referência para elaboração de plano de mobilidade urbana. Secretaria Nacional de Transporte e da Mobilidade - SeMob. 2007.

Mobilize (2017) Estrutura cicloviária em cidades do Brasil (km). Mobilidade Urbana Sustentável. 2017. Disponível em: <http://www.mobilize.org.br/ estatisticas/28/estrutura-cicloviaria-emcidades-do-brasil-km.html> Acesso em: 2 set 2017.

Panter, J., Desousa, C., e Ogilvie, D. (2013) Incorporating walking or cycling into car journeys to and from work: The role of individual, workplace and environmental characteristics. Preventive Medicine, Volume 56, Issues 3-4, Pages 211-217.

PDTU-RMRJ (2013) Plano diretor de transporte urbano da região metropolitana do Rio de Janeiro. Relatório 4, Planejamento e execução das pesquisas, parte III. Diagnóstico da situação atual. Rio de Janeiro, 2015. Disponível em: <http://thecityfixbrasil.com/files/2015/08/Rio-deJaneiro_2013.pdf> Acesso em: 10 de setembro de 2017.

Pereira, R.H.M., Schwanen, T. (2013) Tempo de deslocamento casa-trabalho no brasil (19922009): diferenças entre regiões metropolitanas, níveis de renda e sexo. Texto para discussão IPEA. Brasília. Disponível

em:<http://repositorio.ipea.gov.br/bitstream/11058/958/1/TD_1813.pdf> Acesso em: 20 de junho de 2017. 
Petrunoff, N., Wen, L., Rissel, C. (2016) Effects of a workplace travel plan intervention encouraging active travel to work: outcomes from a three-year time-series study. Revista Public health, Volume 135 , pp. 38 a 47.

Petzhold, G.S., Almeida, B.M.H. (2016) Revelando os custos invisíveis do deslocamento de funcionários para as organizações. XXX Congresso da Associação Nacional de Pesquisa e Ensino em Transportes - ANPET. Rio de Janeiro.

Porto Alegre (1987) Lei Estadual no 6.002, de 02 de dezembro de 1987. Institui o estacionamento pago nas vias públicas da área central do Município e dá outras providências.

Rio-ônibus (2016) Categoria BRS. Disponível em: <http://www.rioonibus.com/ categoria/brs/> Acesso em: 12 de setembro de 2017.

Rocha, A.C.B., Frota, C.D., Kuwahara, N., Peixoto, T.F.A., Balassiano, R. (2006) Gerenciamento da mobilidade: experiências em Bogotá, Londres e alternativas pós-modernas. Pluris 2006, Congresso luso brasileiro para o planejamento urbano, regional, integrado e sustentável. Portugal, 2006.

SAP Consultoria (2016). Pesquisa home office 2016. Campinas. Disponível em: <http://sapconsultoria.com.br/homeoffice/resultados-2016/> Acesso em: 14 set 2017.

São Paulo (1997) Decreto no 37.085, de 3 de outubro de 1997. Regulamenta a lei no 12.490, de 3 de outubro de 1997, que autoriza o Executivo a implantar Programa de Restrição ao Trânsito de Veículos Automotores no Município de São Paulo. Disponível em: <http://www.prefeitura.sp.gov.br/cidade/secretarias/transportes/institucional/index.php?p=7158 > Acesso em: 7 de setembro de 2017.

Seattle (2008) Best practices in transportation demand management. Seattle urban mobility plan. Disponível em: <http://www.seattle.gov> Acesso em: 17 set 2017.

TCRP (2003) Strategies for increasing the effectiveness of commuter benefits programs. Transit cooperative research program. Federal transit administration, Report 87, FTA. Washington. Disponível em: <http://onlinepubs.trb.org/onlinepubs/tcrp/tcrp_rpt_87.pdf> Acesso em: 10 de julho de 2017.

The City Fix Brasil (2013) Projeto Piloto de Mobilidade Corporativa Resultados da Fase I - Berrini. Disponível em: <http://thecityfixbrasil.com/files/2013/09/Andrea-Leal_Banco-Mundial.pdf>. Acesso em: 10 de julho de 2018.

The City Fix Brasil (2017) Por cidades livres de carros: por que a taxação de congestionamento falhou em Nova York. Disponível em: <http://thecityfixbrasil.com/2017/05/19/por-cidades-livresde-carros-por-que-a-taxacao-de-congestionamento-falhou-em-nova-york/> Acesso em: 04 set 2017.

TFL (2017a) The mayor's transport strategy. Transportation for London, 2017 (a). Disponível em: <https://tfl.gov.uk/corporate/about-tfl/how-we-work/planning-for-the-future/the-mayorstransport-strategy?intcmp=2691> Acesso em: 7 de setembro de 2017. 
TFL (2017b) Congestion Charge Zone. Transportation for London. Disponível em: <https://tfl.gov.uk/modes/driving/congestion-charge/congestion-charge-zone?intcmp= 2055> Acesso em: 7 de setembro de 2017.

TFL (2012). Travel in London. Report 5. Transportation for London. Disponível em: <http://content.tfl.gov.uk/travel-in-london-report-5.pdf> Acesso em: 7 de setembro de 2017.

WRI Brasil (2015) Como gerir a demanda para melhorar a mobilidade urbana nas cidades. Disponível em: <http://www.mobilize.org.br/noticias/8683/o-papel-da-gestao-da-demanda-paramelhorar-a-mobilidade-urbana-nas-cidades.html> Acesso em: 9 de setembro de 2017.

WRI Cidades (2017) Empresas gastam 60\% do orçamento com deslocamento dos funcionários em políticas voltadas para o carro. Relatório de Pesquisa. Disponível em: <http://wricidades.org/noticia/empresas-gastam-60-do-or\%C3\%A7amento-com-deslocamentodos-funcion\%C3\%A1rios-em-pol\%C3\%ADticas-voltadas-para> Acesso em: 7 de setembro de 2017. 